\title{
The Study on the Mechanism Influencing Rural Collective Action from the Perspective of Rural Vitalization
}

\author{
Liu Jiagui ${ }^{1}$, Ye Zhonghua ${ }^{1}$ \\ School of Public Policy and Management, University of \\ Chinese Academy of Sciences \\ Beijing 100049, China
}

\author{
Li Lihua ${ }^{2 *}$ \\ Economics\& Management College, Tianjin University of \\ Science \& Technology \\ Tianjin 300222, China
}

\begin{abstract}
The 19th CPC National Congress has proposed a new strategy for rural vitalization. This strategy puts forward higher requirements for rural public improvement. The key problem of public improvement is collective action. Based on Institutional Analysis, Development Framework and Socialecological Framework, this paper discussed the impact of rural collective action on natural conditions changes, social and economic attributes and institutional rules in the context of rural vitalization. And based on this, it also discussed how labor migration affects collective action through social capital mechanism and resource dependency mechanism. Finally, based on the mechanism of how labor migration affecting collective action, it proposed the policy orientation to improve rural collective action.
\end{abstract}

Keywords-Collective Action; Social Capital; Resources Dependency; Rural Vitalization

\section{INTRODUCTION}

The report of the 19th CPC National Congress has first proposed the national new strategy of rural vitalization and taken it as one of the strategies to build up a well-off society and a socialist modernization power in all-round manner. It is the great deployment made by the party for the further development of agriculture and rural area in the new times. The rural revitalization requires to strengthen the rural basic level tasks, and build sound governance system combined with autonomy, rule of law and the rule of virtue, and this just has higher requirement to the public governance in rural area. However, currently, Chinese countryside is just experiencing public governance crisis, general appearing "development antinomy ", a kind of typical phenomenon: in the process of developing rural economy and promoting farmers' income, the hardware facilities in area are perfected gradually. But the opposite is that the appearance, environment and various humanity and ecological environment have not obtained any improvement, but constantly decay instead [1]. In the face of the huge challenge caused by "development antinomy ", domestic understanding for the public governing problem in rural area is not enough, and still can not provide strong support for revitalizing rural governance reform. Therefore, how to verify the reason of decay of the public governance commonly appearing in rural area, according to the combination of autonomy, rule of law and the rule of virtue and seek suitable public governance mechanism for rural development, thereby to reverse the current crisis of the public improvement in rural area, is the problem of great importance and significance for the implementation of rural revitalization strategy in present stage and the perfect of rural governance system.

The core of public governing problem is the collective action problem. In the past over half a century, about how to form effective collective action, international academic community has produced abundant achievement in research, and it successively develops the three generations' collective action, which has become the core content of public governance theoretical system [2-6]. Since the beginning of new century, public governing problem has been receiving the increasing common concerns from domestic scholars. At present, academic community at home has begun to do corresponding research around such problem of public governance, but the whole research range and the degree of depth are very limited. Since the Eleanor Elinor Ostrom relying the outstanding contribution of " How collective action becomes possibility in the public governance" has been honored with Nobel prize in economics in 2009, the discussion of the collective action problem in all kinds of relevant public governance emerges in large numbers rapidly. However, study with theory depth is still rarely seen. How to systematically diagnose collective action problem in the public governance? How to select the best public governance mechanism according to the characteristics of collective action? And how to select suiting measures to local conditions based on the public governance mechanism that is selected? The related study at home still cannot carry out systematically and deeply answer ${ }^{[7]}$ for these questions.

Though as a whole, at present, domestic research to public governing problem is also very weak. However, the proposition of rural area strategy of revitalization, especially the requirement of governing system with sound autonomy, rule of law and the rule of virtue in the rural area, makes the rural area development in future produce unprecedented demand to the theory and practice of public improvement, also provides excellent opportunity of carrying out public governing problem research with Chinese characteristics for domestic scholars. On 
the one hand, the theoretical key variables that influence collective action that identified of international collective action can not explain fully that the public governance of Chinese countryside is absorbed in the problem that generally decays. On the other hand, theoretical public governance mechanism of being advocated of international collective action and public improvement systems are in China, and especially the rural area of China cannot be suitable fully. The fundamental realities of China determine the formation of the public governance system, combined with autonomy, rule of law and the rule of virtue, will receive extensive brawn drain, the extremely influence of factors such as low per capital resources natural endowment, authority system and fast, economical social change. However, at present, variable of these distinct Chinese characteristics factors has not received enough attention from international academic community ${ }^{[8]}$. Therefore, under the requirement of combination of autonomy, rule of law and the rule of virtue, which variation of distinct Chinese characteristics factor will exert influence in the public governance in rural area? And what is the mechanism for the distinct Chinese characteristics factor to influence the public governance in rural area? Systematic and deep answers for these questions, are not only the need for the implementation of rural strategy of revitalization, but the objective requirement for the development of domestic public governance research, enriching the international theory of public governance.

\section{THE PRINCIPAL ELEMENTS INFLUENCING RURAL COLLECTIVE ACTION}

Along with the achievement of economic development in China in recent years, a lot of people in the countryside also begin to enter into the city. Extensive labor's migration has appeared. And this migration causes deep variation of social structure in whole rural areas, even there is tangible hollowization characteristic in a lot of rural areas. Under this social background, the public affairs governance in rural area of our country administers and the supply capacity of public goods has been weakened significantly.

The factor that influences the rural collective action is a lot. According to the diagnosis of Institutional Analysis and Development (IAD) framework and Social-Ecological System (SES) framework influence human collective action by scholars. The factor that influence the rural collective action can be summarized as following three aspects according to the concrete condition of Chinese countryside:

\section{A. The Change of Natural and Geographic Condition}

The change of natural and geographic condition influences the formation of Chinese countryside collective action. First of all, the deterioration of resources supplies. Natural resources condition profoundly influences rural collective action. There is the phenomenon of having a large population and a few lands in China, and therefore in a lot of regions, its per capital stock number especially natural resources amount is few, and it is not strong especially just for carrying out collective action. In addition, the characteristic that the water and soil resources condition constantly worsen occurred in a lot of areas, and there are more natural disasters. To some extent, this also further causes the difficulty of collective action. Secondly, the economic geography of our country has also had great transition at present. Therefore, the connection between peasant household and the market is widely. These very tangible trends are all constantly weakening the motivation that collective action is implemented in the rural area.

\section{B. The Change of Economic and Social Attributes}

The change of economic and social attribute influences the formation of Chinese countryside collective action. First of all, the extensive brawn drain situation occurs in rural areas. In the process of urbanization of whole China, it will inevitably cause labor's outflow. Brawn drain has directly reduced the quantity of participating in individual on collective action and caused the degeneration of collective action. Secondly, more deep variation has also taken place in the population characteristic in village in the last few years. This variation has caused highlighting of hollowization and aging problem. Thirdly, the development of countryside descends for the dependence of agricultural to some extent. Especially a large amount of outflows has appeared in the labor of rural area, which causes the trend of population reduce of each village and family, and this also makes peasant's quantity of rural area descend to some extent. Thus, it will inevitably influence the support of agricultural. Fourthly, there is bigger heterogeneity between each villager because there are more peasants to begin to go out to work, which must further increase regional economic heterogeneous. Thereby, the peasants have difference on the demand for different public things.

\section{The Change of General Game Rule}

The change of general game rule influences the formation of Chinese countryside collective action. First of all, after the reform of relative taxation expenses in rural areas, in the middle of a lot of organizations of political power at the grassroots level, the authority of the sort of system type that itself had is weakened, and the system of a lot of village originally used the sort of " thing view " also begins to have occurred bad effect. Secondly, the autonomous improvement level of rural area also begins to be affected. It is mainly being exactly because in the rural area; the situation of ability drop has appeared in the regime of its basic unit when being organized in the villager mobilized. The peasant does not have very high enthusiasm in participating in public things process, so always just can participate under a kind of passive situation. Thirdly, the whole supervision and management mechanism of rural area is sound not enough. But a kind of effective system is wanted to move more smoothly, all must rely on mutual supervision, so need at first set up supporting penalty mechanism in the rural area. As things go, some traditional customs have still been followed basically in the rural area in the process that whole basic unit can move, or even lean on some rules and regulations for the village and villagers' pledges to manage, and therefore are difficult to play the effect of essence. 


\section{The Mechanism That Causes the Decline of RURAL COLLECTIVE}

The above has just concluded the general impacts on rural collective action, but it just summarized the whole influence of each key factor to collective action. And from the structure of
IAD framework and SES framework, not all factors have direct influence. According to the combing to pertinent literature, this paper thinks that the brain drain factor can exert an influence through the collective action in the rural area with five kinds of intervening mechanisms.

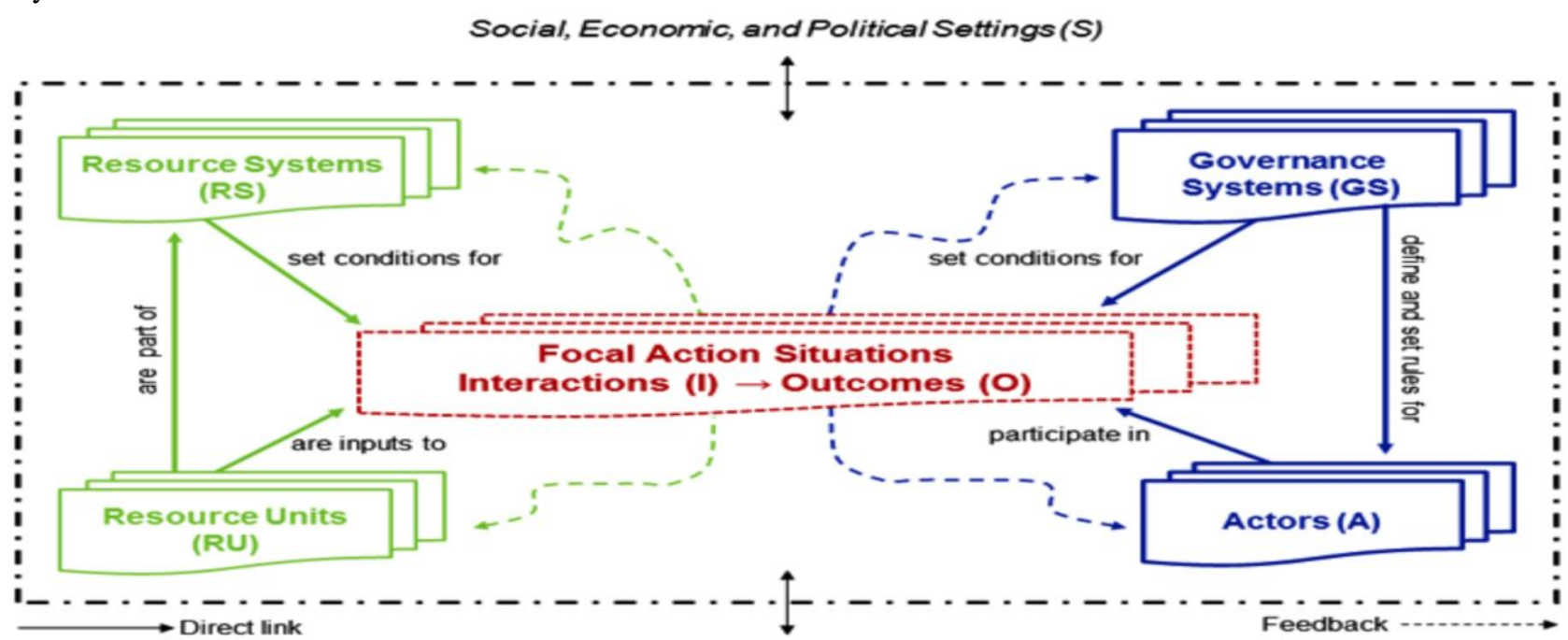

RelatedEcosystems (ECO)

Fig. 1. Institutional Analysis and Development Framework

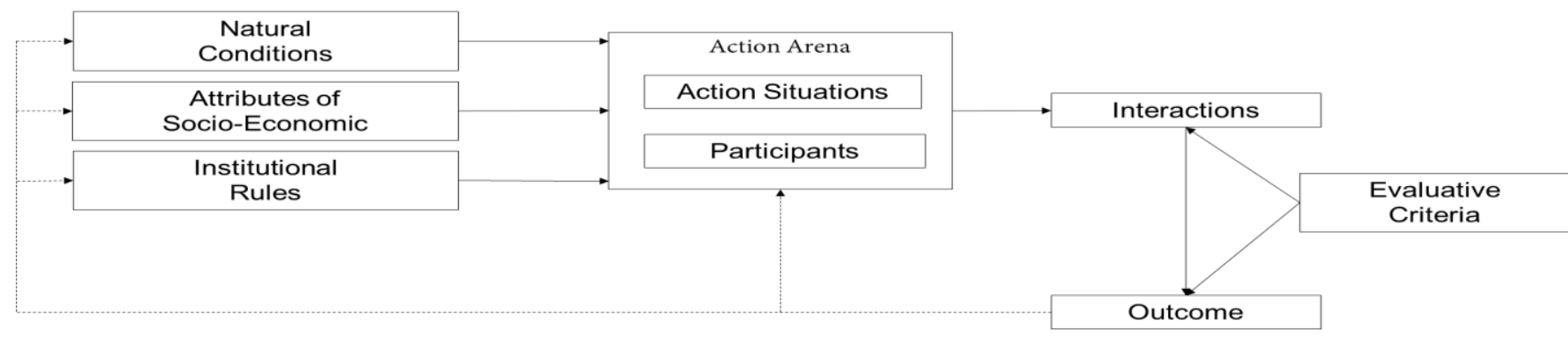

Fig. 2. Socio-Ecological System Framework

The source: Mcginnis M D, Ostrom E. Social-Ecological System Framework: Initial Changes and Continuing Challenges [J]. Ecology \& Society, 2014, 19(2).

The labour is a crucial key element in the whole economy development process. If the labour will still constantly flow to the city from the rural area in future, then for whole modern development economics, it will still be a core of research theme. It can be seen from situation in recent years that some scholars specializing in the rural area political sociology also begin to pay close attention to the constantly problem of outflow of rural area labour. These all can produce great impact to the improvement of whole rural area. Particularly the influence of rural collective action for brawn drain can be analyzed from three aspects. Firstly, if the labour constantly flow, then it must bring difficulty for the improvement of rural area in future. Thus we must reform," city selfish departmentalism ", this economic development mode, and this also is the real key point of extricating oneself from a plight of rural development. Secondly, population constantly flows out from the rural area, or population constantly flows into the village, can be investigated the influence of rural governance from two different dimensions. Thereby two different research visual angles are formed. Thirdly, we can study the problem of rural governance by brawn drain from the corresponding structure function aspects, mainly to study the difficulty.

It can be seen from relevant research theory that the collective action that take in this the process of the development of rural area has certain relation with brawn drain and this contact can be set up through two different intermediate variables in evolution. One of the variables is exactly the actual degree of dependence that the rural area has for resource in the process of development. When more peasant began to enter into the city from the rural area, the peasant did not have high dependence for agricultural. It can be seen from the data in 2012 that peasant household's income agriculturally in China has only accounted for $26.6 \%$. It shows that in the rural area, non-agricultural income has become more 
importantly revenue source of peasant. Therefore, the peasant will not depend on the items like collective's irrigation, which will pose disadvantages for collective action and for the cohesiveness of the society.

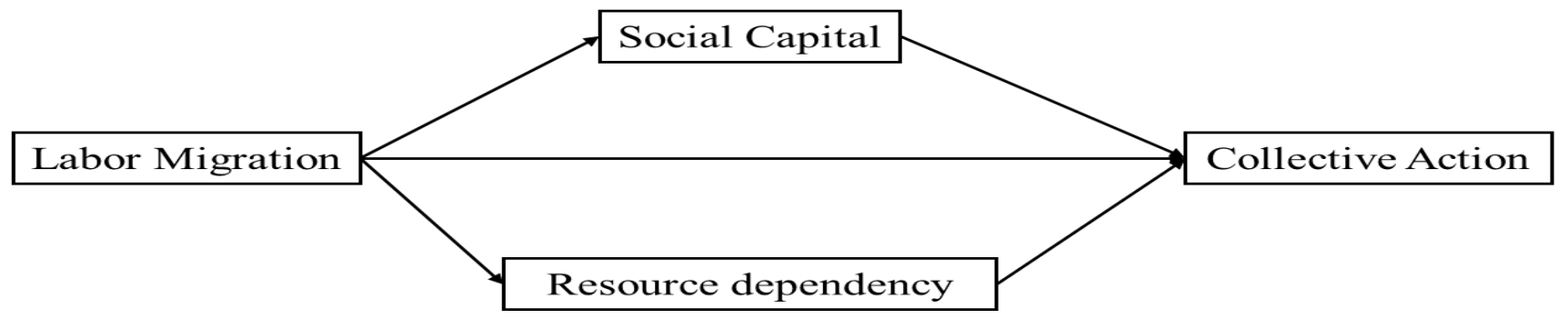

Fig. 3. Mechanisms of how labor migration affecting collective action

\section{CONClusion AND SugGESTIONS FOR POLICIES}

The proposition of rural area strategy of revitalization has set higher requirement for the public governance of Chinese countryside. Based on Institutional Analysis and Development Framework and Social-ecological Framework, this paper discussed influence of rural collective action by the change of natural conditions, attributes of socio-economic and institutional rules, under the background of vitalization in the rural area. And based on this, it also discussed how labor migration affects collective action through two mechanisms of social capital and resource dependency. And finally puts forward that social capital and resource dependency is the main mechanism that labor migration influences rural collective action.

On the basis of the conclusion of the mechanism that influences rural collective action and according to characteristics of each mechanism, this paper puts forward policy orientation of four aspects: first of all, strengthen basic unit's governance ability and public service system construction; inject public leading capacity for the village, reverse the adverse effect that the village brawn drain brings, such as, send first secretary to the village, send " village doctor village's religion " to " two committees in the village ", and build up systems for example establishment of villager council to lift the public leading capacity for the village. Secondly, the poly nary cooperation in develop actively proficient service and rural area is administered, and makes the peasant can obtain more income from agricultural, improves the dependence of peasant to agricultural resource. Therefore, the farmland system reform is the basis, to further activate the different classes of market for factors of production of whole rural area, and need more kinds of multi-form organizational innovations of constant source of encouragement and market innovation and so on. Cultivate some brand-new agriculture management main bodies of more positively and encourage them to attempt multi-form scale management and management in the process of development and encouraged them to carry out agricultural cooperation through specialized mode. Thirdly, greatly develop the service of rural area e commerce and rural area e-government, Unblock the employment channel for peasant household and promote economic heterogeneous reduction between the villager. Need them better to catch this opportunity of Internet revolution, and then internet and agricultural are better combined development, the economic society of the whole rural area of promotion that only in this way can be real develops towards a rational more direction. Fourthly, pay attention to and reinforcement rural culture construction and democracy and the rule of law construction, to promote villager's village sense of ownership, make the villager can have the ability to repair and the social capital that is accumulated in the village again. Through the combination of tradition and modern resource, continue to keep the rural social capital, also further promote sense of ownership and the acceptance of peasant for the village, let the cohesiveness of whole rural society increase.

\section{ACKNOWLEDGMENT}

Authors' profiles: Liu Jiagui, male, a post-doctor of university of the Chinese Academy of Sciences.

Ye Zhonghua, male, doctoral advisor, the college professor of the Chinese Academy of Sciences.

Li Lihua, female, the doctoral candidate of University of Science and Technology of Tianjin. Corresponding author: Li Lihua.

\section{REFERENCES}

[1] Wang Yahua, Gao Rui, Meng Qingguo. Crisis and Response [J]for Public Affair Governance in the Chinese countryside. Tsinghua University's Journal: Philosophy and The Social Sciences Version

[2] Agrawal A. Common Property Institutions and Sustainable Governance of Resources [J]. World Development, 2001, 29(10):1649-1672.

[3] Ostrom E. A General Framework for Analyzing Sustainability of Socialecological Systems [J]. Science, 2009, 325(5939):419-422.

[4] Anderies J M, Janssen M A, Ostrom E. A Framework to Analyze the Robustness of Social-ecological Systems from an Institutional Perspective [J]. Ecology \& Society, 2004, 9(1):243-252.

[5] Ostrom E. A Diagnostic Approach for Going Beyond Panaceas [J]. Proceedings of the National Academy of Sciences, 2007, 104(39):15181-15187.

[6] Araral E. Ostrom, Hardin and the Commons: A Critical Appreciation and A Revisionist View [J]. Environmental Science \& Policy, 2014, 36(3):11-23.

[7] Wang Yahua. Promote Public Things and Administer --- Elinor Ostrom Explore and Application [M]. Beijing: Tsinghua University Press, 2017, 3.

[8] Wang Y, Chen C, Araral E. The Effects of Migration on Collective Action in the Commons: Evidence from Rural China [J]. World Development, 2016, 88:79-93. 